\title{
Fire Resistant Aircraft Unit Load Devices and Fire Containment Covers: A New Development in the Global Air Cargo Industry
}

\author{
Glenn Baxter ${ }^{1}$, Kyriakos Kourousis ${ }^{1}, G$ raham Wild ${ }^{1}$
}

\begin{abstract}
Unit load devices (ULDs) are pallets and containers which are used to carry air cargo, mail and passenger baggage on wide-body aircraft. This paper analyses two important recent developments in the suppression of fires on freighter aircraft - fire resistant containers and fire containment covers for palletised cargo. In July 2013, United Parcel Service (UPS) placed an industry-first order for 1,821 fire-resistant shipping containers; this represented a major milestone in aviation history, offering unprecedented protection from intense fires on the airline's freighter aircraft. The new fire-resistant containers have been designed to withstand intense fires of four hours duration or longer, in order to provide pilots with sufficient time to land their aircraft during such an emergency. Fire containment covers have also been developed to enhance safety on freighter aircraft by isolating individual palletised cargo under special fire retardant covers that are capable of withstanding the intense heat and explosions associated with the ignition of dangerous goods.
\end{abstract}

KEYWORDS: Aircraft unit load devices, Air cargo, Fire containment covers, Fire resistant aircraft containers, Freighter aircraft, Innovation.

\section{INTRODUCTION}

Innovation initiatives are becoming exceptionally important for firms seeking greater competitiveness (Maldonado et al., 2009). In the global air transport industry, an important area of innovation in recent times has been in aircraft unit load devices (ULDs). Unit load devices are pallets and containers which are used to load passengers' baggage, air cargo and mail onto a wide-body aircraft (Lu and Chen, 2011). The International Air Transport Association (IATA) estimates that there are currently around 700,000 ULDs in use by the world's airlines, with an estimated replacement value of close to approximately \$USD1 billion (IATA, 2013a).

As a by-product of the aeronautical design, space is created underneath the wide-body aircraft's passenger deck, where passenger baggage, postal mail and air cargo can be carried (Dempsey and Gesell, 1997). With the introduction of wide bodied aircraft, such as the Boeing B747 and the McDonnell Douglas DC10 aircraft in the 1970s, a large volume of space was required to be filled in the lower deck belly holds of passenger flights, and a faster method of loading and unloading needed to be introduced (Morrell, 2011). Consequently, airlines utilise special containers (aircraft unit load devices) that are designed to fit the lower deck belly holds of their wide-body passenger aircraft, together with specially designed containers to fit the main deck of their freighter aircraft (Baxter, 2011; Morrell, 2011). The utilization of ULDs assists airlines in the standardization and unitization of loading and discharging passenger baggage and air cargo at airports (Lu and Chen, 2012). 
Nearly 60 per cent of world air cargo traffic is carried in freighter aircraft (Boeing, 2013). Wensveen (2011) notes that a freighter aircraft is an aircraft that is expressly designed or converted to carry air cargo, express, and so forth, rather than passengers. Most air cargo is carried in containers or ULDs, with the remainder transported loose in dedicated aircraft lower deck belly-hold compartments (Nobert and Roy, 1998).

Freighter aircraft are operated by the integrators, such as FedEx and United Parcel Service (UPS), dedicated all-cargo carrying airlines, for example, Luxembourg-based Cargolux, and combination passenger airlines that operate freighter aircraft in addition to their scheduled passenger services, for instance, Lufthansa or Korean Airlines. The integrators services are underpinned by the use of dedicated, efficient global multi-modal networks - they own and operate most of their own aircraft, smaller aircraft, trucks, and automated handling and storage facilities (Milenković, 2001). FedEx and United Parcel Service (UPS) are the world's two largest integrators (Bowen, 2012).

The main deck of a freighter aircraft has no amenities and utilises a roller deck to move cargo on and off the aircraft quickly so as to optimise the aircraft turnaround time. A roller deck is an aircraft main deck that is equipped with rollers on the floor, which enables palletized or containerised cargo/ULDs to be pushed or moved into position (Coyle et al., 2011).

In November 2012, the United States National Transportation Safety Board (NTSB) announced recommendations to reduce the harm from fires aboard freighter aircraft. The NTSB recommendations followed three fire-related freighter aircraft accidents that had occurred around the world since 2006 (Jansen, 2012; Sperry, 2012). In response to these recommendations and to suppress fires on freighter aircraft, new innovative fireresistant containers and fire containment covers for palletized cargo have been developed and introduced into service in the world air cargo industry.

\section{THE ROLE OF AIRCRAFT UNIT LOAD DEVICES IN AIRLINE OPERATIONS}

In addition to the ULDs used to carry passenger baggage, airlines use special ULDs for the carriage of air cargo and postal mail, such as containers and pallets. An aircraft pallet and its net and/or igloo, and/or aircraft container, enable individual pieces of air cargo and passengers baggage to be assembled into a standard size unit which expedites the loading and unloading of aircraft having compatible handling and restraint systems during the aircraft's ground turnaround time (Allaz, 2004).

Airlines can select customized types of ULDs for matching the inner contours of the main and lower decks of various widebodied aircraft sizes. Since ULDs are also compatible with a variety of wide-body aircrafts, airlines generally seek the benefit of commonality to purchase as many similar types of ULDs as possible (Lu and Chen, 2012).

The International Air Transport Association (IATA) recognizes a set of standardized ULDs in the form of open pallets, igloos and ULD containers (IATA, 2013b). These ULDs are designed to be compatible with a number of aircraft types and are compatible with cargo terminal handling systems, the airport apron, and the aircraft loading equipment (Ashford et al., 2013).

The dimensions (and capacities) of the aircraft container ULDs used by the world's airlines depend on the aircraft flown and are often closed aluminium devices. Their size and shape depend on whether they are loaded onto lower or upper aircraft decks and whether they have been designed for use on narrow or wide-bodied aircraft (Reynolds-Feighan, 2013). The Airbus A319, A320 and A321 aircraft, for example, offer airlines a containerised baggage/cargo system that saves on the aircraft ground handling turnaround time (Airbus, 2013). Some airline ULDs are customised to fit specific aircraft types, whereas others as noted are compatible with multiple aircraft types (Nobert and Roy, 1998). Also, some containers/ULDs are refrigerated (Reynolds-Feighan, 2013). For example, LD8 containers can only be utilised on Boeing B767 aircraft (Nobert and Roy, 1998), whereas LD9s can be used on Airbus A330, A340 and A380 as well as Boeing B777, 747 and 787 passenger aircraft. LD9s can also be used on Boeing MD11, B777 and 747 freighter aircraft.

The major types of ULDs used by the world's airlines are as follows:

Containers: Rigid bodied containers are used by airlines to protect air cargo (and passenger baggage) and to ease the handling of multiple small, individual consignments of air cargo.

Pallets: Pallets are devices providing a rigid base, suitable for forklifting, on which air cargo consignments can be loaded. The load is secured by nets, and the complete load can be 
manhandled, forklifted, or moved mechanically as a unit (Ashford et al., 2011: 465). Similar to container ULDs, pallet size and shape/contour will vary on the aircraft operated by the airline. Pallets can assist an airline to accommodate larger size consignments (Reynolds-Feighan, 2013). Wide-bodied aircraft can accommodate pallets with standard dimensions of $96 \times 125$ x 64 inches $(244 \times 318$ x $163 \mathrm{~cm})$ within their lower deck belly holds (Ashford et al., 2011). Dedicated freighter aircraft can also accommodate pallets with a $96 \times 125$ inch base, but up to 96 inches (Q6 Contour) or 118 inches (Q7 Contour) $(244 \times 318 \times 243 \mathrm{~cm}$ or $244 \times 318 \times 300 \mathrm{~cm})$ in height on their main deck (CPC, 2012).

Igloos: Igloos are rigid bodied pallets used principally to prevent damage to air cargo or to the interior of the aircraft, where passenger cabins are converted to all-cargo use. A structural igloo is a fully enclosed shell constructed integrally with a pallet base to ensure that cargo conforms to the required aircraft contours. The shell and the pallet base form a single structural unit. A non-structural igloo is a bottomless shell that is designed to fit over an aircraft pallet and to provide shape to loaded cargo. The shell is used in conjunction with the aircraft pallet but does not provide any structural strength (Ashford et al., 2011).

\section{FIRE RESISTANT AIRCRAFT UNIT LOAD DEVICES}

\section{BACKGROUND}

As noted earlier, in November 2012, the United States National Transportation Safety Board (NTSB) announced recommendations to reduce the harm from fires on board freighter aircraft. The NTSB recommended that the United States Federal Aviation Administration (FAA) require active fire-suppression systems in all cargo compartments of aircraft, the development of fire resistant containers/ULDs, and also to improve the early detection of fires within cargo containers (ULDs) and pallets (Jansen, 2012; Sperry, 2012).

The NTSB recommendations followed three fire-related aircraft accidents that had occurred around the world since 2006. In two of the accidents, fires on the aircraft resulted in the deaths of the flight crew and the loss of the aircraft (UPS Boeing B747-400F freighter aircraft in Dubai, UAE in 2010 and an Asian Cargo Boeing B747-400F freighter aircraft that crashed into the ocean off South Korea in 2011) (Jansen, 2012). The third accident occurred in a UPS aircraft at Philadelphia Airport in 2006, in which the crew was able to escape from the aircraft with some minor smoke-inhalation difficulties, but the aircraft was significantly damaged by the fire (Sperry, 2012).

The accident investigations revealed that, during its early stages, a fire burning inside a cargo container or ULD is often concealed. Subsequently, when a fire grows, it quickly burns through the container to threaten the aircraft and its crew (Jansen, 2012). In the three accidents, the fires started within the cargo containers aboard the aircraft, but by the time the aircraft's fire warning system alerted the pilots to the dangers of the fires, there was little time for them to react (Sperry, 2012).

In the United States, Federal regulations require the fire detection systems on cargo airline's aircraft to alert pilots within one minute of a fire starting. However, the NTSB's investigation discovered that current systems detected fire and smoke anywhere from two and half minutes to more than 18 minutes after the fire started on the aircraft (Sperry, 2012).

The NTSB concluded in its report that cargo containers/ ULDs made of flammable materials significantly increase the intensity of the on-board aircraft (Sperry 2012).

The aviation industry, responding to these requirements has taken several actions to design safer equipment. It should be noted that one of the first attempts to mitigate the fire safety issue has originated from the Pan Am flight 103 accident (Ushynskyi, 2009). In particular, in a 1993 FAA report focusing on design of explosion resistant containers, particular requirements for fire and explosion suppression covers were defined (FAA, 1993).

The International Organization for Standardization (ISO) TC20/SC9 'Air cargo and ground equipment' committee has initiated a project on defining a standard for fire safety of air cargo containers (FAA, 2013). Under this task the following standards are going to be developed and published in the coming period:

- ISO 14186:2013 specifies the minimum design and performance criteria and testing methods of fire containment covers (FCCs): either in those cargo compartments of civil transport aircraft where they constitute one means of complying with applicable airworthiness regulations, or secondly, on a voluntary basis, when deemed appropriate by operators to improve 
fire protection in aircraft cargo compartments where airworthiness regulations do not mandate their use (International Organization for Standardization, 2013b).

- SAE AS6453. This SAE Aerospace Standard (AS) is identical to the ISO 14186 standard

- ISO/SAE standard for Fire Resistant Containers (FRC). The FAA is going to develop a unique 'Technical Standards Order' (TSO) referencing this standard (FAA, 2013). The SAE AS6453 and ISO 14186:2013 for Fire Containment Covers (FCC) standards are identical in content, covering covers used in cargo compartments of civil transport aircraft. FAA will include this in the relevant Technical Standards Order (TSO) - TSO C90 (FAA, 2013).

\section{BASICS OF AIRCRAFT FIRES}

\section{Types of fires}

There are four types of fire, classified by the fuel source, which are identified by alphabetical labels.

- Class A: ordinary combustible materials, wood, cloth, paper, or upholstery materials, etc.

- Class B: flammable or combustible liquids, petroleum, greases, solvents, or paints, etc.

- Class C: energised electrical equipment.

- Class D: metals (Dornan 2008).

These are the US identifiers, Europe and Austrália use different letters. Different types of fire require the use of different types of fire extinguishers, specifically, the substance used to extinguish the fire, and whether it removes the fuel, oxygen, or the heat source (or a combination of these).

\section{Fires zones}

A fire zone is an area or region of an aircraft that is designed by the manufacturer to require specific fire protection. As with fire types, fire zones are also identified by alphabetical labels (Flynn, 2001; Tooley and Wyatt, 2009):

- Class A - is the cockpit, cabin, or cargo area, where the fire can be visually detected, reached and combated by crew,

- Class B - is a cargo area, where the fire can be reached and combated by crew, and is detected by a remote fire detection system,

- Class C - is an engine or cargo area, where automated systems are required for both the detecting and extinguishing of the fire,
- Class D - is a cargo area, on passenger aircraft, where the crew cannot reach fire, but the fire is confined within a minimally ventilated fire resistant area (no longer used),

- Class E - is a cargo area on a cargo only aircraft, where the crew cannot reach the fire and ventilation controls are required.

\section{Fire Suppression Systems}

While an aircraft has essential fire suppression systems for the engine and for the lavatories, of interest to this work are portable fire extinguishers and hold fire suppression systems. Portable fire extinguishers are used in Class A and $B$ fire zones, where the crew can use them to actively combat the fire. As with their terrestrial kin, all types of portable fire extinguishers are red in colour, with a different colour label, and each is suited to different types of fires, having a specific effect.

- Red label: water, which is suitable for Class A fires, removing the heat.

- Blue label: dry powder, which is suitable for Class B fires, isolating the oxygen.

- Black label: $\mathrm{CO}_{2}$, which is suitable for Class C fires, isolating the oxygen.

- Green label: Halon 1211, which is suitable for fires of all Classes, stopping the chemical reaction.

Hold fire suppression systems for Class C fire zones are based on Halon 1301 (the two version of Halon have different chemical compositions). Here, the Halon is used as a flooding agent to halt the chemical reaction that takes place in a fire. These suppression systems continue to supply Halon for a period of time after the fire has been extinguished to ensure the heat has dissipated such that re-ignition cannot occur. The specific requirements are an initial volume concentration greater than $5 \%$, and a minimum concentration of $3 \%$ for 60 minutes or 180 minutes under ETOPS (Flynn, 2001).

\section{DEVELOPMENT OF FIRE RESISTANT CONTAINERS AND FIRE CONTAINMENT COVERS} Fire resistant containers (FRC)

The SAE AS 6278 Standard Fire Resistant Container - Design, Performance and Testing Requirements "specifies the minimum design and performance criteria and testing methods of passive fire resistant containers (FRCs) for carriage on aircraft main deck, to be used: (a) either in those cargo compartments of 
civil transport aircraft where they constitute one means of complying with applicable airworthiness regulations, (b) or on a voluntary basis, when deemed appropriate by operators to improve fire protection in aircraft cargo compartments where airworthiness regulations do not currently mandate their use".

On June 19, 2013, the commercial aerospace and defence contractor, AAR, announced the development of a Fire Resistant Container (FRC) that has proved capable of containing an onboard aircraft fire for up to six hours of flight. The AAR subsidiary, Nordisk, partnered with DuPont, and was able to incorporate DuPont ${ }^{\mathrm{TM}}$ Kevlar $^{\circledR}$ brand fibre and Nomex ${ }^{\circledR} \mathrm{XF}$ flame barrier into the innovation, making it the lightest weight FRC on the market. The new FRC is up to 30 per cent lighter than aluminium containers/ULDs (AAR, 2013).

The new FRC is a main deck container designated with the airline industry code "AAD". The code (AAD) refers to its size and shape, which is over 485 cubic feet. The testing of the new FRC strictly measured fire containment, not blast resistance. Depending upon the aircraft's size, anywhere from 24 to $30 \mathrm{FRCs}$ could be accommodated inside the aircraft (AAR, 2013).

On July 22, 2013, United Parcel Service (UPS), one of the world's major integrators, placed an industry-first order for 1,821 fire-resistant shipping containers. The development and introduction of these unit load devices (ULDs) represented a major milestone in aviation history, offering unprecedented protection from intense fires (UPS, 2013b). UPS took delivery of the first of these ULDs in October 2013 and will receive the final ULDs by Spring 2014 (Putzger, 2013).

The new fire-resistant ULDs containers are built with a revolutionary new panel material, MACROLite, that are stretched across an aluminium frame (Croft, 2013) (Putzger, 2013). According to United Parcel Service (2013b), "MACROLite is a fibre-reinforced plastic composite similar to the material used in ballistic body armour". Burn testing conducted by UPS and the United States Federal Aviation Administration (FAA), and witnessed by the National Transport Safety Board (NTSB), has revealed that a ULD constructed of MACROLite panels can contain a fire with a peak temperature of 1,200 degrees Fahrenheit $\left(649^{\circ} \mathrm{C}\right)$ for more than four hours (United Parcel Service, 2013b). Therefore, the new fire-resistant containers have been designed to withstand intense fires of four hours or longer, in order to provide pilots with sufficient time to land their aircraft during such an emergency. The units work by depriving any fires that may break out of oxygen (Putzger, 2013).

\section{Fire containment covers (FCC)}

Air cargo is also carried on the main and lower-deck freighter aircraft belly holds, on aircraft pallets. The relative volumes of cargo carried on aircraft pallets is of significance since fire mitigation measures needed to be developed to suppress fires that break out when cargo is carried on these units. As a result, fire containment covers have been developed to enhance safety on freighter aircraft by isolating individual pallets under a special fire retardant cover (Waldron, 2011).

In recent times, several firms, such as AmSafe and Newtex Industries, have responded to the industry requirement for fire containment covers. The AmSafe fire containment cover provides air cargo airlines with a safer flying environment by mitigating the risk of serious fire caused by undeclared dangerous goods. The fire containment cover operates as a passive system which keeps a fire isolated from other cargo being carried on an aircraft. The AmSafe fire containment cover has been designed for palletised loads of cargo and the cover is comprised of a patented fire retardant fabric with a detachable QuickZip pallet net. The manufacturer reports that the cover "can contain a fire with temperatures of up to $1500^{\circ} \mathrm{F}\left(815^{\circ} \mathrm{C}\right)$ for up to four hours". This combination of net and fabric cover provides a two-way fire barrier that effectively isolates each cargo position on the aircraft and prevents any fire from spreading and escalating. The fire containment cover suppresses the localised threat of the fire on the aircraft through oxygen starvation (AmSafe, 2013).

The AmSafe fire containment cover has many applications but it has been principally designed for palletized loads being transported in the presently unprotected Class E compartments found on the main deck of the majority of freighter aircraft. These covers are also intended to be used to protect the remaining Class $\mathrm{D}^{4}$ lower lobe aircraft belly-holds that are still in operation (AmSafe, 2013).

Another firm that has been developing a fire containment cover is United States-based Newtex Industries, Inc. Since 2007, Newtex has been working closely with aviation experts and airline safety officials to develop a structure capable of withstanding the intense heat and explosions associated with the ignition of dangerous goods, including lithium-ion batteries. The Newtex Z-Block ${ }^{\mathrm{TM}}$ Fire Containment Cover (Fig. 1) has been developed following the outcome of this research and development, and the firm notes that its product is the most advanced protection available for containing deadly smoke and fire in commercial aircraft cargo bays. The system is made of 
Z-Block ${ }^{\mathrm{TM}}$, a polymer coated fabric treated with a proprietary formulation of fire retardants that is able withstand temperatures up to $1800^{\circ} \mathrm{F}\left(980^{\circ} \mathrm{C}\right)$ and offers exceptional resistance to fire, smoke, and weather conditions (Newtex , 2013a). Similar to all of Newtex Industries products, Z-Block ${ }^{\mathrm{TM}}$ is formulated with inorganic materials and will not produce hazardous outgassing (Newtex, 2013b).

$Z$-Block ${ }^{\mathrm{TM}}$ coating and substrate fabrics were originally designed to channel smoke and prevent the spread of fire in aircraft hangars, picture theatres, and large public gathering spaces. The firm has subsequently optimized the fabrics for use in cargo operations by creating a multi-layer system for increased strength and puncture resistance and by adding an interior membrane that contains weather and mildew resistant properties (Newtex, 2013a).

The Z-Block ${ }^{\mathrm{TM}}$ fabric has been tested to the following standards:

- ASTM D6413 - Vertical Flame Resistance

- ASTM E-84 - Surface Flame Spread \& Smoke Density

- FAR 25, Appendix F, Part III and IV - Flame Penetration Resistance \& Smoke Density

- BSS 7239 - Toxicity of Products Combustion (Newtex, 2013a).

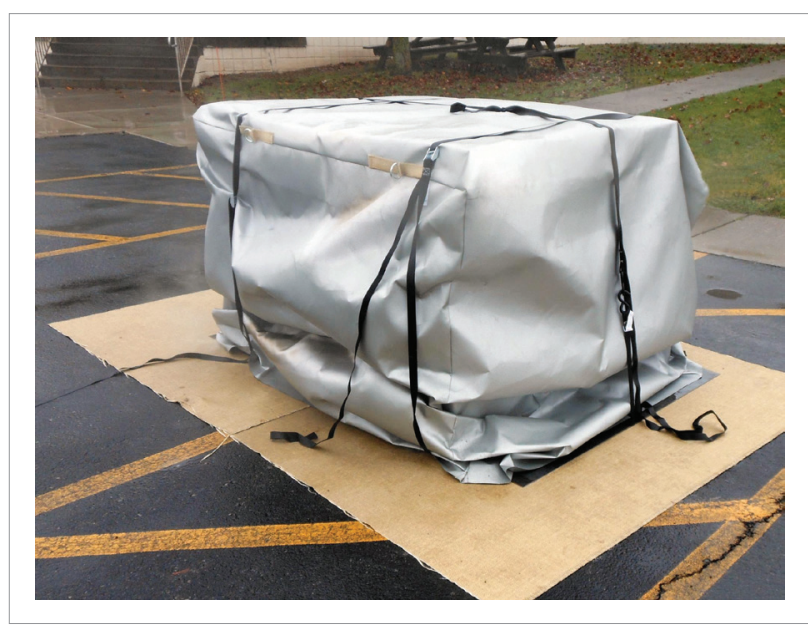

Photo courtesy of Newtex Industries, Inc.

Figure 1. Airline air cargo pallet fire containment cover.
UPS Airlines, for example, has purchased 575 fire containment covers that are able to withstand fires with a peak temperature of $650^{\circ} \mathrm{C} / 1,200^{\circ} \mathrm{F}$ for at least four hours. The airline is deploying these fire containment covers on palletized cargo, and on routes where there are large volumes on electronics being shipped (UPS, 2013a).

\section{CONCLUSIONS}

The carriage of air cargo has become increasingly standardised with the vast majority of world scheduled air cargo traffic now being carried in aircraft unit load devices (ULDs) (Reynolds-Feighan, 2013). Following the investigation into three fire-related freighter accidents that occurred between 2006 and 2012, the NTSB recommended, in October 2012, that the United States Federal Aviation Administration (FAA) require active fire-suppression systems in all cargo compartments of aircraft, the development of fire resistant ULDs, and also to improve the early detection of fires within cargo containers (ULDs) and pallets.

The industry has responded to this critical aviation safety issue. This paper has examined two recent innovations in response to the mitigation and suppression of fires on board freighter aircraft -fire resistant containers and fire containment covers for palletised cargo. Using the latest technologies, this equipment has been designed to suppress fires in the aircraft for around 4 hours thereby providing the pilots with sufficient time to land their aircraft during such an emergency.

\section{ACKNOWLEDGMENTS}

The authors would like to express their sincere gratitude to Newtex Industries, Inc. for permission to use the image of the firm's fire containment cover in this paper.

\section{REFERENCES}

AAR, 2013, "AAR's Nordisk announces lightest weight cargo container now has advanced fire resistance: Providing up to 6 hours of protection, innovation could set a new safety standard", Retrieved in January 3, 2014, from http: / / www.aarcorp.com/news/AAR_Cargo_Container_061913.htm. 
Airbus, 2013, "АЗ20 family: the market leader", Retrieved in January 2 2014, from http://www.airbus.com/fileadmin/media_ gallery/files/brochures_publications/aircraft_families/A320_ Family_market_leader-leaflet.pdf.

Allaz, C., 2004, "History of air cargo and mail from the 18th century". Christopher Foyle Publishing in association with The International Air Cargo Association, London.

AmSafe, 2013, "Fire containment cover", Retrieved in December 7 2013, from http://www.amsafe.com/productsservices/commercial-aviation/cargo-airframe-products/firecontainment-cover/.

Ashford, N. J., Mumayiz, S. A. and Wright, P. H., 2011, "Airport engineering: planning, design, and development of 21 st century airports", 4th ed. , John Wiley \& Sons, Hoboken, NJ.

Ashford, N. J., Stanton, H. P. M.and Moore, C. A. et al. 2013 , "Airport operations", 3rd ed., McGraw-Hill, New York.

Baxter, G. S., 2011, "Restructuring air freight chains: strategic options for competitive advantage", Ph.D. Thesis, Griffith University, Brisbane, Australia.

Boeing, 2013, "World air cargo forecast 2012-2013", Retrieved December 23 2013, from http://www.boeing.com/assets/pdf/ commercial/cargo/wacf.pdf.

Bowen, J. T., 2012, "A spatial analysis of FedEx and UPS: hubs, spokes, and network structure", Journal of Transport Geography, Vol. 24, pp. 419-431.

CPC, 2012, "ULD specifications: pallet", Retrieved in December 23 2013, from http://www.cathaypacificcargo.com/en-us/ helpsupport/uldspecifications / pallet.aspx?code=PMC.\%20 PQP.\%20P6P.

Coyle, J. J., Novak, R. A., Gibson, B. J., Bardi J. Edward, 2011 "Transportation: a supply chain perspective", 7th ed, South-Western Cengage Publishing, Mason, $\mathrm{OH}$

Croft, J., 2013, "UPS takes proactive steps on fire protection", Retrieved in January 3 2014, from http://www.aviationweek. com/Article. aspx?id=/article-xml/awx_07_23_2013_p0599998.xml.

Dempsey, P. S. and Gesell, L. E., 1997, "Air transportation: foundations for the 21st century", Coast Aire Publications, Chandler, AZ.

Dornan, S. 2008, "Industrial Fire Brigade: Principles and Practice", Jones and Bartlett Publishers, Sudbury, MA.

Flynn, T, 1999 "Rule Change: Cargo-Compartment Smoke Detection \& Fire Suppression", AERO Magazine, No. 6.

IATA, 2013a, "ULD update", Retrieved in December 5 2013, from http://www.iata.org/publications/tracker/jan-2013/Pages/ ULDR.aspx.

IATA, 2013b, "IATA ULD regulations", IATA, Montreal-Geneva.

Jansen, B., 2012, "NTSB urges fire-suppression upgrades for air cargo", USA Today, November 28, Retrieved in December 4 2013, from http://www.usatoday.com/story/ todayinthesky/2012/11/28/ntsb-urges-fire-suppressionupgrades-for-air-cargo/1731897/.
Lu, H. A. and Chen, C. Y., 2011, "A time-space network model for unit load device stock planning in international airline services", Journal of Air Transport Management, Vol. 17, No. 2, pp. 94-100.

Lu, H. A. and Chen, C. Y., 2012, "Safety stock estimation of unit load devices for international airline operations", Journal of Marine Science and Technology, Vol. 20, No. 4, pp. 431-440.

Maldonado, M. U., Dias, N. and Varvakis, G., 2009, "Managing innovation in small high-technology firms: a case study in Brazil", Journal of Technology Management and Innovation, Vol. 4, No. 3, pp. 130-142.

Milenković, G., 2001, "Early warning of organizational crises: a research project from the international air express industry", Journal of Communications Management, Vol. 5, No.4, pp. 360-373

Morrell, P. S., 2011, "Moving boxes by air: the economics of international air cargo", Ashgate Publishing, Farnham, UK.

Newtex, 2013a, "Cargo fire containment covers", Retrieved in December 6 2013, from http://www.newtex.com/ EngineeredSystems/FireContainmentCovers/.

Newtex 2013b, "Advanced Fire \& Smoke Barrier", Retrieved in December 6 2013, from http://www.newtex.com/Data/ Documents/ZBlock.pdf.

Nobert, Y. and Roy, J., 1998, "Freight handling personnel scheduling at air cargo terminals", Transportation Science, Vol. 32, No.2, pp. 295-301.

Putzger, I., 2013, "Fire-proof ULDs for UPS sparks heated discussion", Retrieved in December 6 2013, from http://www. aircargonews. net/news/single-view/news/fire-proof-ulds-for-upssparks-heated-discussion. html.

Reynolds-Feighan, A., 2013, "Comparative analysis of air freight networks in regional markets around the globe", Ed. J. H. Bookbinder, Handbook of global logistics: transportation in international supply chains, Springer Science+Business Media, New York, pp. 324-366.

Sperry, T., 2012, "Fire protection aboard freight aircraft unsafe, NTSB says", Retrieved in December 5 2013, from http://edition. cnn.com/2012/11/28/us/cargo-plane-fires/index.html.

Tooley, M. and Wyatt, D., 2009, "Aircraft electrical and electronic systems: principles, maintenance and operation", ButterworthHeinemann, Jordan Hill, UK.

UPS, 2013a, "UPS Airlines fire safety enhancements", October 31, Retrieved in December 6 2013, from http://www.icao.int/ safety/DangerousGoods/DGP\%2024\%20Working\%20Papers/ UPSPresentation.pdf.

UPS, 2013b, "UPS pioneers aviation safety, implements new fire resistant shipping containers", Retrieved in December 6 2013, from http://www.pressroom.ups.com/Press+Releases/ Archive/2013/Q3/UPS+Pioneers+Aviation+Safety, +Implements+ New+Fire-Resistant+Shipping+Containers.

FAA, 1993, "DOT/FAA/CT-93/18, Hardened Luggage Container Design Survey", Retrieved in December 11 2013, from http:// www.dtic.mil/dtic/tr/fulltext/u2/a291485. pdf. 
Fire Resistant Aircraft Unit Load Devices and Fire Containment Covers: A New Development in the Global Air Cargo Industry

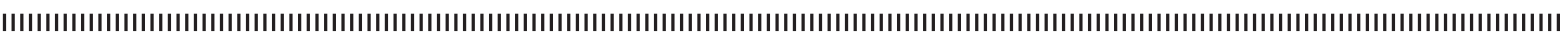

FAA, 2013, "International Aircraft Systems Fire Protection Working Group Meeting, May 22-23 2013", Retrieved in December 11 2013, from http://www.fire.tc.faa.gov/pdf/systems/ May13Meeting/May2013SystemsMin.pdf.

Ushynskyi, S., 2009, "Pan Am flight 103 investigation and lessons learned”, Aviation, Vol. 13, No. 3, pp. 78-86.
Waldron, G., 2011, "AA11: Cargo majors keen on Amsafe fire containment covers", Retrieved in December 7 2013, from http:// www. flightglobal.com/news/articles/aa11-cargo-majors-keen-onamsafe-fire-containment-covers-354052/.

Wensveen, J.G., 2011, "Air transportation: a management perspective", 7th ed., Ashgate Publishing, Farnham, UK. 